\title{
Micropropagación del aliso común para la conservación de su germoplasma
}

\section{San José, M.C. ${ }^{1}$, Janeiro, L.V. ${ }^{2}$, Corredoira, E. ${ }^{1}$}

${ }^{1}$ Departamento de Fisiología Vegetal, Instituto de Investigaciones Agrobiológicas de Galicia, CSIC, Avda de Vigo s/n. Apartado 122, 15080 Santiago de Compostela, España. sanjose@iiag.csic.es

${ }^{2}$ INLUDES. Diputación Provincial de Lugo, Ronda da Muralla 140, 27004 Lugo.

\begin{abstract}
Short title: Micropropagation of common alder

Shoot cultures from adult material of common alder (Alnus glutinosa) were established in vitro. Branches from the canopy and stump sprouts were collected from 20-30-year-old trees. Shoots developed from these branches were used to initiate the cultures using Woody Plant Medium supplemented with $2 \mathrm{mg} / \mathrm{l}$ benzyadenine and $0.5 \mathrm{mg} / \mathrm{l}$ indole acetic acid. The multiplication stage was divided into 3 cycles of 3 weeks each, transferring the shoots to fresh medium at the end of each cycle. Woody Plant Medium was used in this stage supplemented with $0.5 \mathrm{mg} / \mathrm{l}$ indole acetic acid, $0.2 \mathrm{mg} / \mathrm{l}$ benzyladenine (during the first cycle, $0.1 \mathrm{mg} / \mathrm{l}$ for the next two), and $0.5 \mathrm{mg} / \mathrm{l}$ zeatin in the $3^{\text {rd }}$ cycle. Shoots $(1.5-2 \mathrm{~cm})$ from the multiplication stage were rooted in vitro. Rooting percentages getting up to $75 \%$ both in controls and with $0.1 \mathrm{mg} / \mathrm{l}$ indole butyric acid, although the presence of auxin increased the speed of root formation.
\end{abstract}

Keywords: Micropropagation, alder, Alnus, conservation

\section{Resumen}

Título corto: Micropropagación del aliso común.

Se ha establecido un sistema de propagación in vitro a partir de material adulto del aliso común (Alnus glutinosa). Para la iniciación de los cultivos se recogieron ramas de la copa o renuevos basales de árboles de entre 20-30 años, que se forzaron a desarrollar brotes en condiciones controladas. Estos brotes sirvieron para la iniciación de los cultivos utilizando el medio WPM con $2 \mathrm{mg} / \mathrm{l}$ de benciladenina y $0.5 \mathrm{mg} / \mathrm{l}$ de ácido indol acético. La etapa de multiplicación se dividió en 3 ciclos de 3 semanas cada uno, transfiriendo los brotes a medio fresco al final de cada uno de los ciclos, utilizándose el mismo medio que en la etapa de establecimiento (WPM) y como reguladores de crecimiento se añadieron al medio: ácido indol acético $0.5 \mathrm{mg} / \mathrm{l}$ durante $\operatorname{los} 3$ ciclos, benciladenina $0.2 \mathrm{mg} / \mathrm{l}$ (durante el primer ciclo y $0.1 \mathrm{mg} / \mathrm{l}$ durante los dos siguientes), y zeatina $0.5 \mathrm{mg} / \mathrm{l}$ en el tercer ciclo. Brotes $(1.5-2 \mathrm{~cm})$ procedentes de la etapa de multiplicación se enraizaron in vitro, consiguiendo porcentajes de rizogénesis de hasta un $75 \%$ tanto en los controles como en los tratamientos con ácido indol butírico $0.1 \mathrm{mg} / \mathrm{l}$, aunque la presencia de auxina incrementó la velocidad de formación de las raíces adventicias.

Palabras clave: Micropropagación/ Aliso/ Alnus/ Conservación 


\section{Introducción.}

El aliso común (Alnus glutinosa (L) Gaertn, familia Betulaceae) se encuentra ampliamente distribuido por toda Europa desde Irlanda, de donde es originario, hasta Siberia y desde el norte de África hasta Finlandia. Es un árbol de tamaño mediano, con un sistema radical no muy profundo, pero muy ramificado, especialmente adaptado a suelos húmedos. Vive en los márgenes de los ríos y riberas, en los fondos de los valles, zonas inundadas y laderas húmedas, desde el nivel del mar hasta los $1700 \mathrm{~m}$. Prefiere sustratos ácidos y ricos en limos, con humedad permanente y aguas frecuentemente renovadas, si bien se adapta fácilmente al crecimiento en suelos más pobres debido a la asociación simbiótica que establece en sus raíces con hongos actinomicetos del género Frankia.

Los alisos se encuentran ampliamente representados en los ecosistemas riparios. Estos ecosistemas tienen un amplio rango de propiedades ecológicas que los hace particularmente importantes en la conservación del paisaje. Actúan como corredores de dispersión, facilitando el intercambio de individuos entre distintos hábitats (Mech y Hallett, 2001; Haddad et al., 2003) y además sirven para mitigar los impactos derivados de la explotación forestal y de la plantación de especies foráneas (Boothoyd et al., 2004; Homyack y Haas, 2009). En los últimos años, se ha detectado la muerte de un gran número de ejemplares de aliso como consecuencia de una enfermedad causada por el hongo Phytophthora alni. El tipo estándar se ha denominado $P$. alni subsp alni, existiendo otras dos subespecies: uniformis y multiformis (Brasier et al., 2004). Santini et al. (2003, 2006) comprobaron que además del aliso, el castaño, el nogal y los cerezos silvestres también presentan cierta susceptibilidad al ataque del hongo. Los árboles enfermos presentan una lesión necrótica en la raíz y cuello del árbol, pudiéndose observar externamente un exudado oscuro, las hojas son más pequeñas, menos numerosas y frecuentemente amarillentas, además incrementa anormalmente la fructificación. Entre las especies de alisos europeos, A. incana, A. viridis, A. cordata y A. glutinosa, esta última es la que crece mayoritariamente en Galicia y la que presenta una mayor susceptibilidad al ataque del hongo. En el aliso común, las lesiones producidas por $P$. alni subsp alni frecuentemente rodean completamente el tronco de estos árboles (Webber y Gibbs, 2006). La enfermedad apareció por primera vez en el Reino Unido en 1993 y, desde entonces, se ha extendido rápidamente por toda Europa, representando una seria amenaza para la ecosistemas riparios (NAPPO, 2006). En España se detectó hace unos 10 años y en la actualidad está extendida a lo largo de toda la Cornisa
Cantábrica, desde Navarra hasta el golfo Ártabro, así como por la Cornisa Atlántica Gallega y en áreas limítrofes castellano-leonesas y portuguesas.

El reconocimiento de la importancia de estas especies en el mantenimiento ecológico de los ríos conlleva la necesidad de seleccionar técnicas descritas en la biotecnología vegetal que nos permitan la conservación de su diversidad genética. La crioconservación de germoplasma (almacenamiento en nitrógeno líquido) se considera una metodología de gran utilidad para la conservación de recursos fitogenéticos, pero para que esta técnica sea realmente eficaz es necesario desarrollar previamente protocolos de micropropagación que nos permitan la regeneración de plantas a partir del material crioconservado (Reed, 2008).

Los trabajos de propagación in vitro realizados hasta la fecha en este género son escasos. Garton et al. (1981) establecieron los primeros protocolos para A. glutinosa y desde entonces se han escrito diversos trabajos sobre la micropropagación de distintas especies del género Alnus con material procedente de diversos orígenes (juvenil y adulto) (Tremblay et al., 1986; Barchchi, 1988; Lall et al., 2005), si bien no se han definido con precisión los protocolos para su desarrollo in vitro. En este trabajo se ha estudiado el establecimiento, multiplicación y enraizamiento de brotes de aliso con el fin de establecer los protocolos que nos permitan desarrollar posteriormente métodos de conservación del germoplasma de esta especie que se encuentra severamente amenazada.

\section{Material y métodos}

\subsection{Establecimiento}

Se recogieron ramas de la copa de 4 árboles de entre 25-30 años de la Reserva de la Biosfera "Terras do Miño" (R 1-4), situada en la provincia de Lugo, y renuevos basales de un árbol de entre 20-25 años que había sido talado en las inmediaciones de Santiago de Compostela (G 1). Para todos los clones se efectuó la recogida de material en el mes de junio y para los clones R1 y R3 también en noviembre. Las estaquillas de 20$25 \mathrm{~cm}$ se situaron en posición vertical en bateas con perlita humedecida y se forzaron a brotar en una cámara de crecimiento a $25^{\circ} \mathrm{C}$ con una humedad relativa de entre el $80-90 \%$ con un fotoperíodo de $16 \mathrm{~h}$ y una intensidad luminosa de 90-100 $\mu$ mol m-2 s-1. Después de 2-3 semanas se habían desarrollado nuevos brotes que nos sirvieron para obtener los explantos iniciales para el establecimiento de los cultivos. Brotes de una longitud de 2-4 cm, desprovistos de hojas, se esterilizaron mediante inmersión en alcohol de $70^{\circ}$ durante $20 \mathrm{~s}$, seguido de una solución al $0.6 \%$ de cloro libre (Tabletas Millipore $\left.{ }^{\circledR}\right)$ con $1 \mathrm{mg} / \mathrm{l} \mathrm{de}$ Tween 80 durante 8 min, seguido de 3 aclarados con agua destilada estéril. Para la iniciación de los 
cultivos se utilizaron los segmentos apicales y nodales $(5-8 \mathrm{~mm})$ que se situaron en posición vertical en los tubos de cultivo $(30 \times 150 \mathrm{~mm})$ conteniendo $16 \mathrm{ml}$ del medio de establecimiento. El medio mineral está compuesto por las sales y vitaminas del Woody Plant Medium (WPM, Lloyd y McCown, 1980), sacarosa 3\%, agar Difo 0.7\%, $2 \mathrm{mg} / \mathrm{l}$ de benciladenina (BA) y $0.5 \mathrm{mg} / \mathrm{l}$ de ácido indol acético (AIA). El pH de los medios se ajustó a 5.7 antes de autoclavarlos a $121^{\circ} \mathrm{C}$ durante 20 min. Para prevenir el daño causado por los exudados, cada explanto se trasladó al lado opuesto del mismo tubo al día siguiente de su establecimiento. Los explantos se transfirieron a medio fresco de igual composición cada 2 semanas hasta su estabilización.

Todos los cultivos se mantuvieron en una cámara de crecimiento con un fotoperíodo de $16 \mathrm{~h}$ y una temperatura de $25^{\circ} / 20^{\circ} \mathrm{C}$ (día/noche), con una

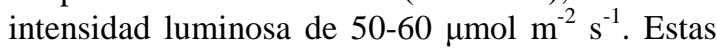
condiciones se aplican también durante las etapas de multiplicación y enraizamiento descritas a continuación.

\subsection{Multiplicación}

Las experiencias se llevaron a cabo con brotes del clon G1 desarrollados en la etapa de establecimiento. Esta etapa se dividió en tres ciclos de 3 semanas cada uno, los brotes se transferían a medio fresco al final de cada uno de los ciclos. El medio mineral es el mismo que el utilizado en la etapa anterior (WPM) y como reguladores de crecimiento se utilizaron, AIA 0.5 $\mathrm{mg} / \mathrm{l}$ en todos los ciclos, BA $0.2 \mathrm{mg} / \mathrm{l}$ durante las tres primeras semanas (1er ciclo), reduciendo su concentración a $0.1 \mathrm{mg} / \mathrm{l}$ durante las 6 siguientes ( $2^{\circ}$ y 3 er ciclo), en el 3er ciclo se añadieron además $0.5 \mathrm{mg} / \mathrm{l}$ de zeatina $(\mathrm{Z})$. Se utilizaron los segmentos apicales y basales de los brotes (8-10 $\mathrm{mm}$ de longitud). Posteriormente, se realizó otro ensayo, utilizando sólo los explantos basales, para estudiar el efecto sobre el desarrollo de los brotes de la adición de $\mathrm{Z}$ en distintos momentos de la etapa de multiplicación, bien en el tercer ciclo o bien durante los 3 ciclos en los que se dividió esta etapa.

Los datos sobre el número total de brotes, número de brotes de entre $0.5-1 \mathrm{~cm}$, mayores de $1 \mathrm{~cm}$, longitud del brote más largo y porcentaje de explantos que reaccionan en cada una de las experiencias se recogieron al final de los 3 ciclos (9 semanas). Se utilizaron 18 explantos por experimento y todas las experiencias se repitieron 3 veces.

\subsection{Enraizamiento}

Brotes de $15-20 \mathrm{~cm}$ de longitud de los cultivos aislados de los cultivos en multiplicación del clon $\mathrm{R}$ 4, se transfirieron al medio de enraizamiento (WPM con los macronutrientes reducidos a la mitad). Para la inducción de las raíces se ensayó la adición al medio de 0-0.1 mg/l de ácido indol butírico (AIB) durante los 7 primeros días, al cabo de los cuales los brotes se transfirieron al mismo medio sin auxina. Después de 4 semanas se procedió a la recogida de los datos: porcentaje de brotes que habían enraizado, número de raíces y longitud de la raíz más larga por brote enraizado. Se estudió así mismo la cinética de la formación de las raíces adventicias en cada uno de los tratamientos. Se utilizaron 10 brotes por tratamiento y la experiencia se repitió dos veces.

El análisis estadístico de los resultados se efectuó con la aplicación del test t para la comparación de medias y el test X2 para los porcentajes, con un valor de significación en ambos casos de $\mathrm{p} \leq 0.05$.

\section{Resultados y discusión.}

\subsection{Establecimiento}

El desarrollo de las yemas laterales de las estaquillas tuvo lugar en todos los genotipos a partir de los 10-15 días de su instalación en el fitotrón. Los porcentajes de brotación oscilaron entre un $14 \%$ (R1) a un $100 \%$ (G1) dependiendo del genotipo. En aquellos clones en los que se efectuaron dos recogidas de material, en junio y noviembre, este último mes mejoró notablemente los resultados obtenidos (R1: $14 \%$ en junio frente a un $68 \%$ en noviembre; R3: $31 \%$ en junio frente a un $75 \%$ en noviembre). Las tasas de contaminación (principalmente causada por hongos) también se vieron afectadas por la época de recogida oscilando entre un $9-27 \%$ en junio a un $59-62 \%$ en noviembre. Todos los genotipos brotaron en el fitotrón, si bien posteriormente mostraron considerables diferencias en su comportamiento in vitro, consiguiendo estabilizar únicamente los clones R1, R4 y G1. El resto de los clones muestran un declive progresivo en los sucesivos subcultivos que nos condujo a la perdida total del material in vitro. Los tiempos de estabilización oscilaron entre los 5-7 meses para los clones G1 y R4 respectivamente, a 12 meses para el R1. Estas variaciones en el comportamiento in vitro pueden ser atribuidas tanto a sus diferencias genéticas (R1-R4), como al origen del material (G1). El material del clon G1, procedente de renuevos basales, responde mejor al cultivo que los otros clones procedentes de ramas de la copa, este material retiene ciertas características juveniles que favorecen su respuesta in vitro. En la micropropagación de material adulto de Quercus rubra, Vieitez et al. (1993a) observan notables diferencias en la reactividad entre material procedente de brotes epicórmicos (31-85\%) y material procedente de la copa del árbol (4-24\%). También se han utilizado con éxito renuevos basales en la micropropagación de otras especies de roble y castaño adulto (Vieitez et al., 1985, 1986). Bonga et al. (2010) señalaron que aunque la facilidad de propagación vegetativa tiende a disminuir a medida que se 
incrementa la edad del árbol, en algunos casos se pueden encontrar ciertos tejidos que mantienen características juveniles, como los renuevos basales, brotes epicórmicos y los brotes que se forman en las raíces. La recogida de los brotes desarrollados en el fitotrón se efectuó al cabo de 34 semanas cuando éstos habían alcanzado una longitud de entre $1-3 \mathrm{~cm}$. Los explantos apicales responden mucho mejor al cultivo que los basales, en estos últimos se produjo una mayor necrosis, así como la formación de callo que a partir de las superficies de corte tiende a englobar el explanto.

\subsection{Multiplicación}

Como ya ha sido señalado para otras especies, como castaño y haya (San José et al., 1988, Vieitez et al., 1993b), el tipo de explanto utilizado influyó de forma significativa el desarrollo de los cultivos. Los mejores resultados en cuanto al número de brotes de entre $0.5-1 \mathrm{~cm}$ (2.1 frente a 0.6) y número total de brotes (3.1 frente a 1.7) se obtuvieron con los explantos basales, no observándose diferencias significativas en el número de brotes mayores de $1 \mathrm{~cm}$, ni en los porcentajes de respuesta (Tabla 1). Las diferencias entre los dos tipos de explantos evaluados pueden considerarse consecuencia de la presencia de yemas axilares en un estado de desarrollo más avanzado en los segmentos basales, así como una manifestación de la dominancia apical, de forma que las tasas de multiplicación se podrían incrementar mediante la eliminación de los ápices.

Numerosos autores han utilizado la BA (0.02-05 $\mathrm{mg} / \mathrm{l}$ ) para el desarrollo de brotes de origen juvenil de A. glutinosa (Tremblay et al., 1986), aunque se obtienen peores resultados cuando se trabaja con material de origen adulto. Estas dificultades pueden considerarse asociadas a cambios en las características de crecimiento que frecuentemente acompañan la transición del estado juvenil al adulto (Poething, 1990). Lall et al. (2005) observaron el desarrollo de brotes muy elongados, pero sin ramificar, y abundante formación de callo al utilizar BA durante la etapa de multiplicación de aliso de origen adulto. Estos autores sugieren que la utilización de inhibidores del transporte de auxinas favorece la acción de la BA, si bien presentan algunos problemas de vitrificación. En nuestro caso, la realización de un ciclo de multiplicación estándar de 4 semanas incluyendo BA y AIA como reguladores de crecimiento, dio como resultado brotes de pequeño tamaño y bajas tasas de multiplicación (datos no mostrados). Basándonos en trabajos previos realizados en Fagus sylvatica por Vieitez et al. (2003), en los que estos autores sugieren la realización de subcultivos sucesivos para mejorar las tasas de multiplicación, mejorando así el aporte de nutrientes para el desarrollo de los brotes, dividimos cada etapa de multiplicación en 3 ciclos de subcultivos de 3 semanas cada uno transfiriendo los brotes a medio fresco al final de cada uno de los ciclos, consiguiéndose de esta forma mejorar considerablemente la calidad de los brotes obtenidos (Figura 1). Por otra parte, Vieitez et al. $(2003,2009)$ comprobaron que la utilización conjunta de BA y Z favorecía el desarrollo de brotes y hojas en cultivos en multiplicación de Fagus sylvatica, Quercus alba y Q. bicolor. Estos autores señalan un posible desajuste en el balance de zeatina endógena o de sus derivados en los brotes desarrollados en medios suplementados únicamente con BA. En la Tabla 1 se pueden observar el efecto que sobre el desarrollo de los brotes tiene la adición de zeatina en distintos momentos del ciclo de multiplicación del aliso. La incorporación de $\mathrm{Z}$ en la etapa de multiplicación mejoró la calidad de los brotes, observándose un incremento significativo del número de brotes mayores de $1 \mathrm{~cm}$ y como consecuencia de la longitud del brote más largo cuando esta citoquinina estuvo presente en los 3 ciclos en los que se dividió la etapa de multiplicación, si bien el número de brotes de entre 0.5 y $1 \mathrm{~cm}$, así como el número total de brotes fue mejor en el tratamiento con $\mathrm{Z}$ en el tercer ciclo, por lo cual establecemos como protocolo su incorporación en el tercer ciclo, lo que nos permite abaratar notablemente los costes de mantenimiento.

\subsection{Enraizamiento}

Aplicando los protocolos descritos en la etapa de multiplicación, obtuvimos brotes del clon R4 suficientemente elongados para proceder a su enraizamiento para la obtención de plantas completas de origen adulto. Tremblay et al. (1986) señalan la facilidad de enraizamiento de brotes de distintas especies de Alnus procedentes de cultivos in vitro, obteniéndose en muchos casos porcentajes del $100 \%$ en presencia o ausencia de auxina en el medio. No obstante, estos autores apuntan que en A. glutinosa la inclusión de AIB en el medio aumentó el número de raíces formadas por brote enraizado y redujo el tiempo requerido para obtener el pleno enraizamiento. En la Tabla 2 se muestran los resultados obtenidos en nuestro trabajo, los porcentajes de enraizamiento fueron similares en ambos tratamientos (75-76 \%). La presencia de AIB $0.1 \mathrm{mg} / \mathrm{l}$ en el medio, aunque disminuyó el número de raíces formadas por brote enraizado, aceleró de forma considerable la emergencia de las raíces. Así se pudo observar que en los brotes tratados con auxina la salida de las primeras raíces se inicia a partir de los 8 días y su formación se había completado sobre el día 12 , mientras que en los controles se completa sobre el día 18 (Gráfico 1, Figura 2). A. glutinosa y otras especies que están sometidas a inundaciones en sus hábitats naturales son capaces de producir raíces adventicias en la base de los troncos en respuesta a la inundación de sus raíces y de las partes más bajas de sus tallos (Gill, 1975). Probablemente el gran contenido de auxinas 
endógenas en brotes maduros de A. glutinosa sea consecuencia de la adaptación a estos hábitats. El comportamiento in vitro de brotes de aliso se ve fuertemente influenciado por el contenido endógeno de estos reguladores (Lall et al., 2005).

\section{Conclusiones}

Los resultados obtenidos muestran la posibilidad de micropropagar distintos individuos de $A$. glutinosa como una forma de preservar su diversidad genética que se encuentra amenazada en diferentes puntos de nuestra geografía como consecuencia del ataque del hongo Phytophthora alni.

\section{Agradecimientos}

Los autores quieren agradecer la asistencia técnica de José Carlos Suárez San Martín, así como la colaboración del alumno de FP en prácticas Daniel García Areán. Esta investigación ha sido financiada por el INLUDES (Diputación Provincial de Lugo) mediante un Convenio CSICINLUDES.

\section{Referencias}

Barghchi, M. 1988. Micropropagation of Alnus cordata (Loisel.) Loisel. Plant Cell Tiss. Organ Cult. 15: 233-244

Bonga, J.M., Klimaszewska, K.K., von Aderkas, P. 2010. Recalcitrance in clonal propagation, in particular in conifers. Plant Cell Tiss. Organ Cult. 100: $241-254$

Boothroyd, I.K.G., Quinn, J.M., Langer, E.R., Costley, K.J., Steward, G. 2004. Riparian buffers of pine plantation logging on New Zealand streams: 1 Riparian vegetation structure, stream geomorphology and periphyton. For. Ecol. Manage. 194: 199-213

Brasier, C.M., Kirk, S.A., Delcan, J., Cooke, D.E.L., Jung, T., Man in't Veld, W.A. 2004. Phytophthora alni sp nov. and its variants: designation of emerging heteroploid hybrid pathogens spreading on Alnus trees. Mycol. Res. 108: $1172-1184$

Garton, S., Hoiser, M.A., Read, P.E., Farnham, R.S. 1981. In vitro propagation of Alnus glutinosa Gaertn. HortScience 16: 758-759

Gill, C.J. 1975. The ecological significance of adventitious rooting as a response to flooding in woody species, with special reference to Alnus glutinosa. Flora 164: 85-97

Haddad, N.M., Bowne, D.R., Cunningham, A., Danielson, B.J., Levey, D.J., Sargent, S., Spira, T. 2003. Corridor use by diverse taxa. Ecology 84 : 609-615

Homyack, J.A., Haas, C.A. 2009. Long-term effects of experimental forest harvesting on abundance and reproductive demography of terrestrial salamanders. Biol. Conserv. 142: 110121

Lall, S., Mandegaran, Z., Roberts, A.V. 2005. Shoot multiplication in cultures of mature Alnus glutinosa. Plant Cell Tiss. Organ Cult. 83: 347350

Lloyd, G., McCown, B.H. 1980. Commerciallyfeasible micropropagation of mountain laurel, Kalmia latifolia, by use of shoot tip culture. In: Proceedings of the International Plant Propagators' Society 30: 421-427

Mech, S.G., Hallett, J.G. 2001. Evaluating the effectiveness of corridors: a genetic approach. Conserv. Biol. 15: 456-474

NAPPO. 2006. Update on alder Phytophthora and potential new hosts. Phytosanitay Alert System

Poeting, R.S. 1990. Phase change and the regulation of shoot morphogenesis in plants. Science 259: 923-930

Reed, B.M. 2008. Cryoconservation-practical considerations. In: Reed, B.M. (ed.), Plant Conservation: A Practical Guide, Springer, NY

San José, M.C., Ballester, A., Vieitez, A.M. 1988. Factors affecting in vitro propagation of Quercus robur L. Tree Physiol. 4: 281-290

Santini, A., Biancalani, F., Barzanti, G.P., Capretti, P. 2006. Pathogenicity of four Phytophthora species on wild cherry and Italian alder seedlings. J. Phytopathol. 154: 163-167

Santini, A., Barzanti, G.P., Capretti, P. 2003. Ssusceptibility of some mesophitic hardwoods to alder Phytophthora. J. Phytopathol. 151: 406-410

Tremblay, F.M., Perinet, P., Lalonde, M. 1986. Tissue culture of Alnus spp. with regard to symbioses. In: Bajaj, Y.P.S. (ed.), Biotechnology in Agriculture and Forestry. Vol. 1. Trees I. Springer-Verlag, Berlín, Heidelberg

Vieitez, A.M., Corredoira, E., Ballester, A., Muñoz, F., Durán, J., Ibarra, M. 2009. In vitro regeneration of the important North American oak species Quercus alba, Quercus bicolor and Quercus rubra. Plant Cell Tiss. Organ Cult. 98: 135-145

Vieitez, A.M., Ferro, E.M., Ballester, A. 1993b. Micropropagation of Fagus sylvatica L. In Vitro Cell Dev. Biol.-Plant 29: 183-188

Vieitez, A.M., Pintos, F., San José, M.C., Ballester, A. 1993a. In vitro shoot proliferation determined by explant orientation of juvenile and mature Quercus rubra L. Tree Physiol. 12: 107117

Vieitez, A.M., San José, M.C., Sánchez, M.C., Ballester, A. 2003. Micropropagation of Fagus spp. In: Jain S.M. and Ishii K. (eds.), 
Micropropagation of Woody Trees and Fruits. Kluwer Academic Publishers, The Netherlands

Vieitez, A.M., San José, M.C., Vieitez, E. 1985. In vitro plantlet regeneration from juvenile and mature Quercus robur L. J. Hort. Sci. 60: 99-106

Vieitez, A.M., Vieitez, M.L., Vieitez, E. 1986. Chestnut (Castanea spp). In: Bajaj, Y.P.S (ed.),
Biotechnology in Agriculture and Forestry. Vol. 1. Trees I. Springer-Verlag, Berlín, Heidelberg

Webber, J.F., Gibbs, J.N. 2006. Phythophthora disease of alder in the UK. In: C. Brasier, C., Jung, T. and Oßald, W. (eds.), Progress in Research on Phytophthora Diseases of Forest Trees. Forest Research, Farnham, Surrey, UK 
Tabla 1. Efecto del tipo de explanto (apices o bases) y de la adición de zeatina en distintos momentos de la etapa de multiplicación sobre el desarrollo de brotes de A. glutinosa

\begin{tabular}{|c|c|c|c|c|c|c|}
\hline Tratamiento & $\begin{array}{l}\text { Tipo de } \\
\text { explanto }\end{array}$ & $\begin{array}{c}\% \\
\text { respuesta }\end{array}$ & $\begin{array}{l}\mathrm{N}^{\circ} \text { brotes } \\
0.5-1 \mathrm{~cm}\end{array}$ & $\begin{array}{l}\mathrm{N}^{\circ} \text { brotes } \\
\geq 1 \mathrm{~cm}\end{array}$ & $\begin{array}{l}\mathrm{N}^{\circ} \text { total } \\
\text { brotes }\end{array}$ & $\begin{array}{c}\text { Longitud brote } \\
\text { más largo }\end{array}$ \\
\hline Zeatina & Apicales & $98.0 \mathrm{a}^{1}$ & $0.6 \pm 0.14 \mathrm{a}$ & $1.0 \pm 0.10 \mathrm{a}$ & $1.7 \pm 0.17 \mathrm{a}$ & $16.3 \pm 0.70 \mathrm{a}$ \\
\hline & Basales & $96.3 \mathrm{a} \mathrm{A}$ & $3.2 \pm 0.17 \mathrm{~b} \mathrm{~A}$ & $1.0 \pm 0.11 \mathrm{a} \mathrm{A}$ & $3.1 \pm 0.15 \mathrm{~b} \mathrm{~A}$ & $15.0 \pm 0.79 \mathrm{~b} \mathrm{~A}$ \\
\hline $\begin{array}{l}\text { Zeatina en } \\
\text { los } 3 \text { ciclos }\end{array}$ & Basales & $100.0 \mathrm{~A}$ & $1.5 \pm 0.18 \mathrm{~B}$ & $1.3 \pm 0.16 \mathrm{~B}$ & $2.8 \pm 0.21 \mathrm{~B}$ & $16.5 \pm 0.79 \mathrm{~B}$ \\
\hline
\end{tabular}

${ }^{1}$ En cada columna los valores que muestran la misma letra no son significativos para $\mathrm{p} \leq 0.05$

Tabla 2.- Efecto de la adición de AIB $0.1 \mathrm{mg} / \mathrm{l}$ sobre el enraizamiento de brotes A. glutinosa

\begin{tabular}{lccc}
\hline Tratamiento & $\begin{array}{l}\text { Porcentaje de } \\
\text { enraizamiento }\end{array}$ & $\begin{array}{l}\mathrm{N}^{\circ} \text { medio de raíces por } \\
\text { brote enraizado }\end{array}$ & $\begin{array}{l}\text { Longitud media de la } \\
\text { raíz más larga por } \\
\text { brote enraizado (mm) }\end{array}$ \\
\hline Control & $75.0 \mathrm{a}^{1}$ & $3.4 \pm 0.34 \mathrm{a}$ & $37.3 \pm 2.57 \mathrm{a}$ \\
AIB $0.1 \mathrm{mg} / \mathrm{l}$ & $76.2 \mathrm{a}$ & $2.9 \pm 0.45 \mathrm{~b}$ & $37.9 \pm 3.84 \mathrm{a}$ \\
\hline
\end{tabular}

${ }^{1}$ En cada columna los valores que muestran la misma letra no son significativos para $\mathrm{p} \leq 0.05$ 


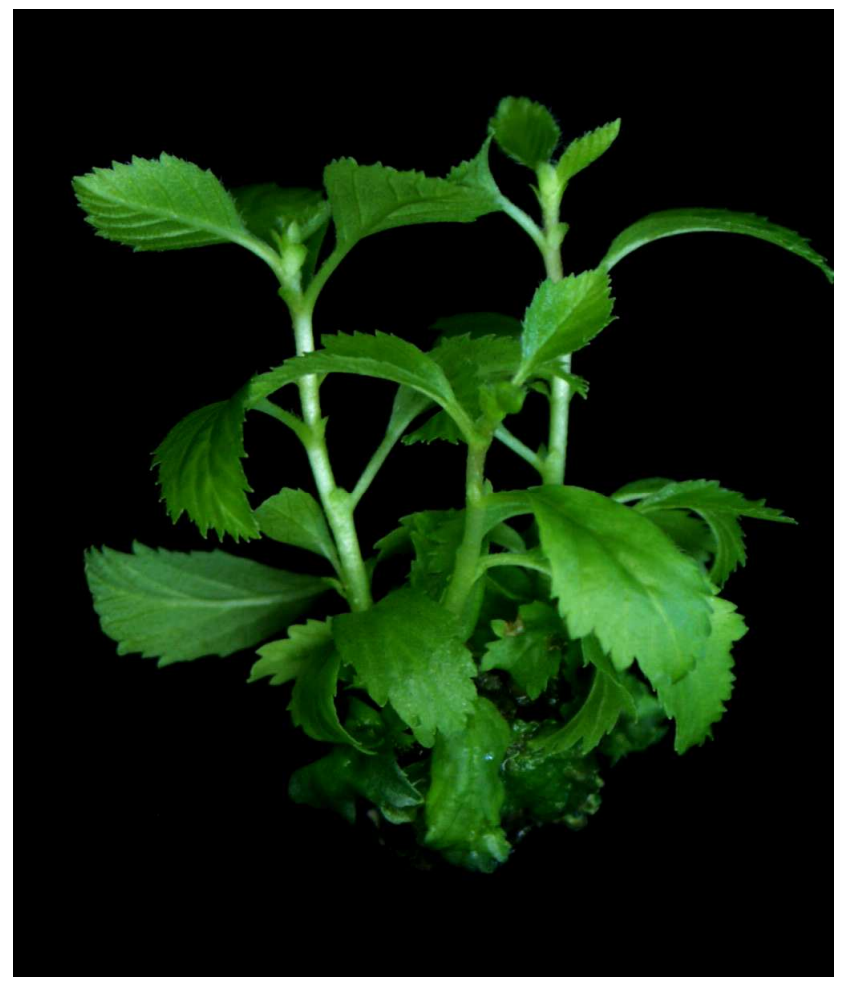

Figura 1. Brotes de A. glutinosa, clon G1, obtenidos en la etapa de multiplicación

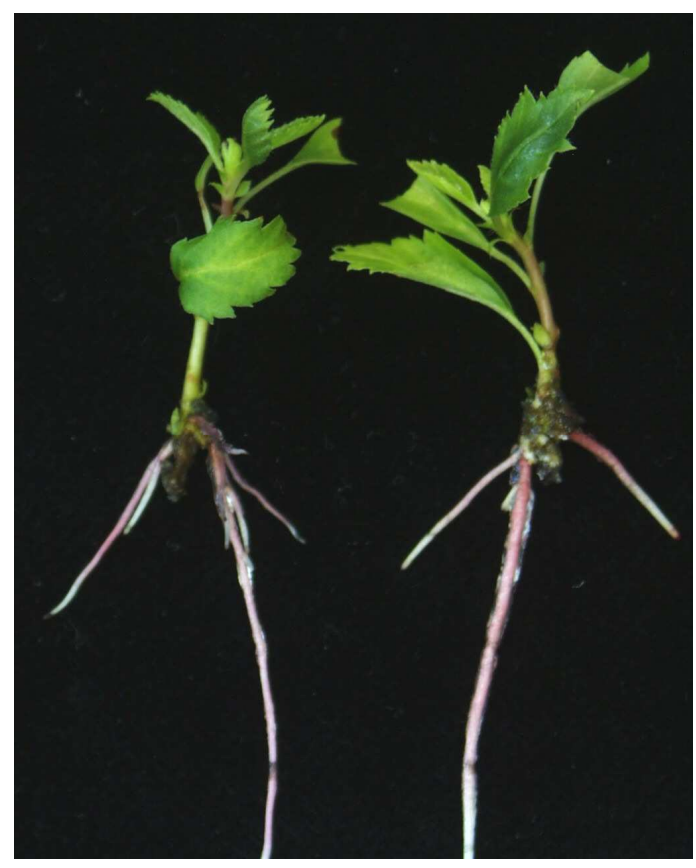

Figura 2. Desarrollo de las raíces adventicias en brotes de A. glutinosa, clon R4, en el tratamiento con AIB $0.1 \mathrm{mg} / \mathrm{l}$ durante 7 días 